\title{
Food Supply Chain: Consumer Preferences
}

\author{
Imanuella Romaputri Andilolo \\ Management Department \\ Fac. of Economics and Business, Universitas Mataram \\ Mataram, Indonesia \\ imanuelita@gmail.com
}

\author{
Ikma Citra Ranteallo \\ Dept. of Sociology \\ Fac. of Social and Political Science, Universitas Udayana \\ Denpasar, Indonesia
}

\begin{abstract}
There are many papers that independently argue either for or against short or long food supply chain management. This paper attempts to combine both sides of arguments for short and long food supply chain through literature research. The arguments for short supply chain referred to in this paper as altruistic in nature. For a balanced view point, another set of list is compiled for arguments in support of long food supply chain or global food supply. Arguments for global supply referred to in this paper are viewed with economical value. Interviews are conducted on consumers of varying backgrounds as to their preferences on fruits and vegetables supplied through both long and short supply chain. Main research question is, when faced with the choice of altruism or economical values, which one will prevail? A look at the role of popular culture in shaping those preferences will also be investigated. Suggestions for managerial implications will be provided.
\end{abstract}

Keywords-food supply chain; consumer preference; short food supply chain management;long food supply chain management

\section{INTRODUCTION}

At present, consumers in many parts of the world enjoy an abundance of choices or alternative products and produce. The open markets and free trade areas have been the catalyst for this phenomenon. For example, fruits from China such as apples and pears can be easily found in remote parts of Indonesia. This is also due in most part to modern supply chain networks that focus on creating value in supply chain relationships by increasing the benefits of the product for the customers, reducing the costs of the product, improving delivery service, or reducing the time of delivery (1) (2). Other increasing focus of supply chain network is green supply chain with its main concern on lowering carbon footprints across the supply chain (3). This paper focuses on produce, namely fruits and vegetables that are procured locally as well as imported.

A research was conducted in India to assess the consumers' preferences for food and grocery products and market attributes (4). A similarity can be drawn with this research in that the respondents and research location are both in emerging markets with growing purchasing power. Although the attributes used for food and grocery preferences of the consumers were, in order of importance, cleanliness/freshness followed by price, quality, variety, packaging, and non-seasonal availability, this paper would like to investigate consumer preference when faced with the choice of buying local produce or imported produce.
This is a preliminary research in nature, thus further improvement will be necessary. Several initial assumptions were made for the investigation. Imported food produce is assumed to be cheaper than local produce, as industrial agriculture is defined as capital and resource intensive, largescale, high yielding, and mechanized with monocultural cropping systems (5). On this basis, the assumption that a highly efficient industrial agri-food system can deliver cheaper exported produce is formed.

\section{LITERATURE REVIEW}

\section{A. Food Supply Chain}

Currently there are two separate and unequal agri-food system, namely the industrial agriculture and the sustainable agriculture. These are based on the competing values, differential social and environmental impacts, and unequal power relations, among others. Industrial agriculture refers to long food supply chain, intensive farming of few crops, large production capacity and are normally bought in big supermarket chains, among others (6). Sustainable agriculture on the other hand, emphasizes on short food supply chain, diverse productivity, small to moderate size production capacity, protection and enhancement of the environment and contributes to the welfare of communities (5) (6). According to previous research, small farms can be equally, if not more, productive per unit area than large-scale agribusiness, are better stewards of natural resources, and contribute more to local community and economic development (5). Arguably small farms producing specialty crops may contribute to farmland preservation, local labor markets, and less carbon footprint in bringing the produce to market.

A research was conducted in Ho Chi Minh City, compares the traditional versus modern food system. As modern food system is growing rapidly in most developing Asian countries through increase presence of modern retail supermarkets, the research found that the modern sector exclusively focuses on quality and their supply chains are generally more efficient than the traditional sector (7). Increase in efficiency may translate into cheaper produce sold in the modern sector. However, additional production cost such as packaging is not factored in at the traditional sector.

Over the years, there have been global scares with dioxin pollution, classical swine fever, and avian influenza, among others. These events have lead consumers to become more critical and wish to be informed about the origins and processes of food procurement, safety levels, production 
methods, hygiene, use of genetically modified feed, application of pesticides, and other environmental issues like food miles and carbon footprints (8).

The findings of a research on the sustainability of the supply chain for fresh potatoes in Britain proposed that economic and related market factors associated with staying in business and maintaining competitive advantage were the dominant concern for all supply chain participants. Greater importance, however, is now given to social and environmental factors both as influences on decision making and as indicators of business performance (9). Thus, quality, safety and environmental conformity are increasingly becoming factors in consumers' buying decision. Although more research are needed to determine if consumers are willing to pay more for sustainable products.

Health is another increasingly important issue raised when discussing food supply chain. Organic products are positively associated with health. Although they are known to be more expensive and hard to find than its non-organic counterpart, an Italian study reveals that most consumers judge them positively (10). However, the research fails to indicate whether this positive association actually translates into purchase. Nevertheless, consumers increasingly demand good, tasty and nourishing products, because pleasure and wellbeing are important values.

Understanding the importance of certain issues may not automatically translate into real action, more so when other equally important issue became an alternative. In the marketplace, consumers often face situations that require choosing among several alternatives. In reality, many decisions involving choice among several desirable alternatives can be difficult and give way to a more fundamental kind of preference- the decision whether or not to choose (11). In retrospect, this paper attempts to investigate which out of two alternatives will consumers prefer; short or long food supply. Furthermore, assuming that long food supply is cheaper than short food supply, which will be their preferred choice.

\section{B. Consumer Preference}

"Food taste preferences are now inextricably linked to artistic design and media manipulation, as in advertising and in creating social status and prestige to the extent of elevating to a fashionable cult status some individuals who are presenters of cookery competition programs, food fashion writers and celebrity chefs" (12).

Ericksen (6) stated three elements that describe accessibility of food: affordability, allocation, and preference.

"Affordability: the purchasing power of households or communities relative to the price of food. The determinants of affordability include pricing policies and mechanisms, seasonal and geographical variations in price, local prices relative to external prices, the form in which households are paid, income, and wealth levels. Allocation: the mechanisms governing when, where, and how food can be accessed by consumers. Markets are a key determinant of food allocation; government policies often are designed to correct market failures by allocating food to remote areas or at lower prices. Social capital influences informal allocation processes (e.g., within households), while at a broader scale social and political capital in urban areas influence where supermarkets are located. Both social and political capital influence rules for fishing, hunting, and gathering in rural communities. Preference: social or cultural norms and values that influence consumer demand for certain types of food. Determinants may be religion, season, advertising, preparation requirements, human capital, tastes, customs, and female labor force participation.'

\section{THE RESEARCH}

The premise of this research is to find the preference of informants when faced with the hypothetical choice of cheaper imported produce or more expensive local produce. For the sake of this research, the hypothetically more expensive local produce yet beneficial in other aspects are portrayed as the altruistic choice. On the other hand, the hypothetically cheaper imported produce albeit with some drawbacks are categorized as the economical choice. Although many literature reviews support short food supply chain as environmentally friendly and healthier, among others, long food supply chain or global food supply chain provide a wider variety of produce and processed food otherwise not available in the local market. More often produce from global or long supply chains are also cheaper than those produced locally. This is due to global efficiency in the supply chain.

\section{A. Methodology}

The research conducted for this paper used a sample survey method to collect data from the informants using a set of interview questions. Data collected were processed using descriptive analyses. The total informant for this research was 60 persons.

\section{B. The Interview}

The interview sheet contains 16 questions. The first 7 questions focused on the informants' details, such as gender, age range, location, income, occupation, civil status, and number of children if any. Most of these questions are standard identity questions. However, in this particular event, the researcher also asked the number of children based on the general assumption that large families would consume a lot more than small or single families thus tend to opt for cheaper produce especially when income is limited.

Food produce is identified as vegetables and fruits. Processed food such as sausages, nuggets etc. are not included. Questions 8-16 are more focused on the preference of the informant. The list of questions from number $8-16$ is set below:

8. Circle the place where food produce are usually purchased (usually = everyday up to three times a day): a. local market; b. supermarket; c. warung / kiosk; d. foot traders; e. others.

9. In general, would you choose to purchase local / imported food produce?

10. List the local food produce that you usually purchase. 
11. List the imported food produce that you usually purchase.

12. List the reasons of purchasing local food produce.

13. List the reasons of purchasing imported food produce.

14. If imported food produce is cheaper than local food produce, which one will you buy: imported / local? Why?

15. Assuming imported food produce is cheaper, at what price difference will you buy imported food produce? a. Rp1000 - Rp3000; b. Rp3000 - Rp5000; c. Rp5000 - Rp8000; d. Rp8000 - Rp10.000; e. > Rp10.000

16. Choose the statement that best fits you:

a. I will purchase food produce that is cheaper regardless its origin.

b. I will purchase local food produce even if it is more expensive.

\section{Limitations}

Limitations of this research were time and resources. Future research would benefit in expanding the number of samples and sample locations. This research was conducted during the month of Ramadhan where majority of food produce experience a rise in price. Better timing would be more beneficial and should provide clearer distinction between the two choices of short and long food supply chain. Another aspect for further research is to eliminate the hypothetical aspect of research question by presenting a concrete sample. Many respondents cannot distinguish the origin of some types of food produce whether they are procured locally or imported.

The authors acknowledge the simplicity of this research. Through literature review conducted, other types of analyses such as conjoint analysis (13) (14) were used as analytical tool. However, the authors maintain the simplistic nature of this research as a preliminary research. Furthermore, the reason why no attributes were provided for informants to rank from was intentionally as not to influence the informants with their response.

\section{RESULTS AND FINDINGS}

Only a selection of interesting findings will be presented in this paper:

Q14: Assuming imported food produce is cheaper, which one would you purchase: imported/ local.

Out of 50 informants, 25 persons will purchase local food produce. Over $50 \%$ of that cited helping local farmers and improve the local economy as their main reason to choose local food produce. The other half perceive local food produce as of better quality, natural or organic compare to imported food produce. On the other hand, 23 persons choose imported food produce with $73 \%$ swayed by the assumption that imported food produce is cheaper. Others cite the variety of produce and better quality as their main reason to choose imported food produce.

Q15: Assuming imported food is cheaper, at which price range you will purchase imported food in comparison to local food: I will purchase imported food if it is ... CHEAPER:

a. $\operatorname{Rp} 1000-\operatorname{Rp} 3000$

b. $\operatorname{Rp} 3000-\operatorname{Rp} 5000$

c. $\operatorname{Rp} 5000-\operatorname{Rp} 8000$

d. $\operatorname{Rp} 8000$ - Rp 10.000

e. $>\operatorname{Rp} 10.000$

The most price range chosen was between Rp3000 Rp5000 cheaper with 14 out of 50 informants choosing b. There were 10, 4, and 11 informants chose price range a, c, and d, respectively. Anybody that chooses price range of over Rp10,000 we classified as hardcore local foodie. The assumption is that at this price range, preference for local food produce is so strong that only at over Rp10,000 price difference will they purchase imported food produce. There were 11 informants that chose price range e. Surprisingly not all 11 informants had chosen local food produce in Q14. Only 8 out of 11 had previously chosen local food produce over the cheaper imported food produce. Therefore, 8 informants are classified as real hardcore local foodie. Interesting to note is that almost all are less than 30 years old (only 2 are under 35 years old). Although the sample is small, it must not be underestimated that the younger generation has different priorities and they represent a new market.

Q16: Choose related statement between:

A: I will purchase cheaper food produce regardless of its origin; or

B: I will only purchase local food produce even if it's more expensive

To this, $68 \%$ choose statement B, i.e. 34 out of 50 informants. Whereby, 32 of those are under 35 years old.

Recommendations: The research can be elaborated further for the use of global food supplier as well as local food supplier in understanding their consumer base. Purchasing preferences and consumer awareness are shifting with the under 35 becoming more conscious of local food movements, the creation of new social identity, and new popular social image through social media and the internet.

\section{ACKNOWLEDGMENT}

Both authors thank the Committee of the $1^{\text {st }}$ UPI Global Conference on Business, Management and Entrepreneurship 2016 for organizing this event. We would also like to thank our students for their assistance in conducting the research. Last but not least, we thank all those involved in making this paper possible.

\section{REFERENCE}

[1] Logistics and Supply Chain Management: Creating Value-Adding Networks3rd EditionHarlowFinancial Times Prentice Hall2005

[2] Value-based differentiation in business relationships: gaining and sustaining key supplier status Ulaga, W.; Eggert, A.1Journal of Marketing119-136 
[3] Modeling carbon footprints across the supply chain Balan Sundarakani, Robert de Souza, Mark Goh, Stephan M. Wagner, Sushmera ManikandanInt. J. Production Economics43-50

[4] Buying behaviour of consumers for food products in an emerging economy Jabir Ali; Sanjeev Kapoor; Janakiraman Moorthy2British Food Journal109-124

[5] Understanding agri-food networks as social relations Agriculture and Human Values279-283

[6] Conceptualizing food systems for global environmental change research Global Environmental Changedoi:10.1016/j.gloenvcha.2007.09.002

[7] Traditional vs. Modern Food Systems? Insights from Vegetable Supply Chains to Ho Chi Minh City (Vietnam) Jean-Joseph Cadilhon; Paule Moustier; Nigel D. Poole; Phan Thi Giac Tam; Andrew P. Fearne1Development Policy Review31-49

[8] Systems for sustainability and transparency of food supply chains Current status and challenges P.M. Wognum; Harry Bremmers; Jacques H. Trienekens; Jack G.A.J. van der Vorst; Jacqueline M. Bloemhof Advanced Engineering Informatics65-76

[9] The sustainability of the supply chain for fresh potatoes in Britain $\mathbf{K}$. Vasileiou; J. Morris4Supply Chain Management: An International Journal317-327

[10] Consumer motivations in the purchase of organic food: A means-end approach Raffaele Zanoli; Simona Naspetti8British Food Journal643653

[11] Consumer Preference for a No-Choice Option 2The Journal of Consumer Research215-231

[12] Food taste preferences and cultural influences on consumption Len Tiu Wright; Clive Nancarrow; Pamela M.H. Kwok5British Food Journal348-357

[13] The Use of Conjoint-Analysis for Measuring Preferences in SUpply Chain Design Industrial Marketing Management

[14] Conjoint Analysis in Consumer Research: Issues and Outlook Journal of Consumer Research

[15] The use of conjoint-analysis for measuring preferences in supply chain design Industrial Marketing Management27-35 